\title{
The potential impact of anaemia of chronic disease in COPD
}

\author{
T. Similowski*, A. Agustí ${ }^{\#}$, W. MacNee ${ }^{\uparrow}$ and B. Schönhofer ${ }^{+}$
}

ABSTRACT: Anaemia of chronic disease (ACD), with chronically low levels of circulating haemoglobin, is an immune driven abnormality that occurs in many inflammatory diseases, and also in chronic heart failure. Although chronic obstructive pulmonary disease (COPD) is "traditionally" associated with polycythaemia, the systemic inflammation that is now recognised as a feature of COPD makes it a possible cause of ACD. If present in COPD, anaemia could worsen dyspnoea and limit exercise tolerance.

Preliminary evidence suggests that anaemia in COPD patients may be more prevalent than expected, concerning $10-15 \%$ of patients suffering from severe forms of the disease. A database study conducted in 2,524 COPD patients being prescribed long-term oxygen therapy has shown that a low haematocrit is a strong predictor of survival in this population, before body mass index, and is associated with more hospitalisations and a longer cumulative duration of hospitalisation. COPD patients with low haemoglobin levels have a poorer prognosis than COPD patients with normal haemoglobin levels in the event of acute gastrointestinal bleeding or after elective aneurysm repair. Raising haemoglobinaemia through transfusion decreases minute ventilation and work of breathing in COPD patients.

These preliminary evidences point to the need to study the prevalence of anaemia, and its physiological and clinical impact in chronic obstructive pulmonary disease. When this body of knowledge is available, the question of the putative benefits of raising haemoglobinaemia in chronic obstructive pulmonary disease will have to be addressed.

KEYWORDS: Anaemia, anaemia of chronic disease, chronic obstructive pulmonary disease, erythropoietin

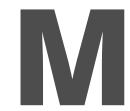
any chronic diseases have been shown to affect haematopoiesis, resulting in shortening of red blood cell (RBC) lifespan and sequestration of iron in macrophages, and leading to the so-called anaemia of chronic disease [1]. Over the past few years, the clinical scope of this syndrome has stretched beyond its traditional chronic infectious, inflammatory and neoplastic causes, to include heart failure [2]. In heart failure, an association between anaemia of chronic disease (ACD) and mortality is likely [3].

Theoretically, chronic obstructive pulmonary disease (COPD) is another candidate likely to be associated with ACD, when considered in relation to the already-known systemic effects of the disease [4]. This is suggested by the systemic inflammation that is common in COPD and can be evidenced by raised levels of inflammatory markers, cytokines and chemokines in some patients [5-7], with inflammatory peaks during exacerbations $[8,9]$. However, COPD is commonly considered as a cause of polycythaemia rather than of anaemia. Recent reports may challenge this view. The World Health Organization (WHO) defines anaemia as a haematocrit level $<39 \%$ in males and $36 \%$ in females [10]. Yet, in the COPD population from which CELLI et al. [11] derived the prognostic value of the BODE index (body mass index, airflow obstruction, dyspnoea and exercise capacity), the average haematocrit value of the patients who died was $39 \pm 5 \%$. Amongst 101 patients with an average forced expiratory volume in one second (FEV1) of $37 \pm 2 \%$ predicted, JoHN et al. [12] found a prevalence of anaemia of $13 \%$. In a database cohort of 2,524 COPD patients being prescribed long-term oxygen therapy for the first time, CHAMBELLAN et al.

\section{AFFILIATIONS}

*Service de Pneumologie, Groupe Hospitalier Pitié-Salpêtrière,

Assistance Publique-Hôpitaux de

Paris, and UPRES EA2397 Université

Paris VI Pierre et Marie Curie, Paris, France.

\# Servei Pneumología, Hospital Universitari Son Dureta, Palma de Mallorca, Spain.

"Respiratory Medicine Unit, Royal Infirmary of Edinburgh, Edinburgh, Scotland, UK.

${ }^{+}$Abteilung für Pneumologie und Intensivmedizin, Klinikum Hannover Oststadtkrankenhaus, Hanover, Germany.

\section{CORRESPONDENCE}

T. Similowski

Service de Pneumologie \& Reanimation

Groupe Hospitalier Pitie-Salpetriere

47-83 Bd de l'Hopital

75651 Paris 13

France

Fax: 33142176708

E-mail: thomas.similowski@psI.

ap-hop-paris.fr

Received:

December 152004

Accepted after revision:

August 152005

SUPPORT STATEMENT

In 2003, T. Similowski, A. Agusti and W. McNee were appointed as advisors by AMGEN Inc. (Thousand Oaks, CA, USA) during exploratory discussions about the possible clinical relevance of raising haemoglobin levels in chronic obstructive pulmonary disease patients through the administration of recombinant erythropoietin. This programme did not come into being.

European Respiratory Journal Print ISSN 0903-1936 
[13] reported a prevalence of anaemia of $12.6 \%$ in males and $8.2 \%$ in females, higher than that of polycythaemia defined by an haematocrit level $>54 \%$ ( $8.4 \%$ of the patients). These data are not sufficient to ascertain the prevalence of anaemia in COPD in general and to determine whether or not it is greater than in matched control populations. Nevertheless, they do suggest that anaemia in COPD patients should be the object of intensified research in the near future, and that pulmonary physicians should be aware of its putative mechanisms and clinical consequences.

This review first summarises the mechanisms of ACD, then relates existing data on systemic inflammation in COPD to these mechanisms and, finally, considers what the clinical impact of anaemia could be in patients with COPD.

\section{MECHANISMS OF ANAEMIA OF CHRONIC DISEASE: AN OVERVIEW}

ACD is immune driven and mainly inflammatory in nature [1]. From a pathophysiological point of view, there are three putative mechanisms that are thought to lead to ACD, namely: shortened RBC survival, iron homeostasis dysregulation and impaired bone marrow erythropoietic response [1, 2, 14].

Shortened RBC survival is thought to occur as a result of raised levels of the cytokines interleukin (IL)- 1 and tumour necrosis factor (TNF). An inverse correlation has been shown between IL-1 and RBC survival in anaemic patients with rheumatoid arthritis [15]. In animal models and in vitro studies, TNF has also been implicated in reducing RBC survival [16]. These cytokines blunt the erythropoietin (EPO) response to physiological stimuli that tend to increase EPO production [17]. In turn, the decreased availability of EPO causes neocytolysis, or selective haemolysis of the nascent RBCs [18]. This, hypothetically at least, contributes to the shortened RBC life seen in ACD.

Impaired iron mobilisation or utilisation is thought to be a result of upregulation of ferritin mRNA, caused by the circulating cytokines IL-1 and interferon (INF)- $\gamma$. This increases translation of ferritin, trapping iron that would otherwise be available for erythropoiesis [19]. Erythropoiesis is also inhibited by downregulation and internalisation of the transferrin receptor. The cytokines TNF and IL-1 are also thought to be involved in impeding iron utilisation through other unknown mechanisms [14].

Finally, impaired marrow erythropoietic response is thought to be the result of IL- 1, TNF- $\alpha$ and transforming growth factor- $\beta$ inhibiting renal EPO production. IL-1, TNF- $\alpha$ and INF- $\gamma$ also inhibit the erythroid progenitor response to EPO, and INF- $\gamma$ causes apoptosis of the erythroid progenitors (a result of a process possibly mediated by ceramide and nitric oxide). At the protein and mRNA levels, INF- $\gamma$ also downregulates EPO receptor expression $[2,14]$.

Several cytokines and chemokines therefore interfere at different levels in haematopoiesis, and thus have a key role in ACD. Indeed, raised cytokines in anaemic patients have been demonstrated in clinical studies. Research from 105 patients with ACD and rheumatoid arthritis, and 127 nonanaemic but arthritic controls established that TNF- $\alpha$, IL-1 $\beta$ and IL- 6 serum levels were significantly higher in patients with
ACD than those without [20]. However, further research into the exact nature of the pathogenesis of ACD and the interplay between the different mechanisms outlined above, will be necessary to elucidate these complex pathophysiological mechanisms and, hence, to develop appropriate therapeutic regimens for these patients.

\section{COPD AS A PUTATIVE CAUSE OF ANAEMIA OF CHRONIC DISEASE}

Increased inflammation in the lungs, but also a systemic inflammatory response is now a well-established concept in COPD [5-7, 21]. In brief, patients with COPD often exhibit raised levels of inflammatory markers in the peripheral blood (C-reactive protein (CRP), fibrinogen, leukocytes, proinflammatory cytokines such as IL- $1 \beta$, IL- 6 or TNF- $\alpha$, chemokines such as IL- 8 , and monocyte chemotactic protein (MCP)- $\alpha$; fig. 1). The expression of neutrophil adhesion molecules is increased, the release of neutrophils from the bone marrow is also raised and there are changes in neutrophil function and deformability. This may lead to increased sequestration of neutrophils in the pulmonary microcirculation [23-25]. During smoking or exacerbations of COPD, these changes are magnified [7-9]. This systemic inflammation may be an important determinant of the nutritional imbalance that characterises many patients with COPD. Indeed, some studies reported statistical associations between weight loss in COPD and the raised serum levels of TNF- $\alpha$ and other cytokines [2629]. Other studies indicated that both nutritional depletion and inflammation had a negative prognostic value in COPD [30].

The systemic inflammatory profile of COPD, as described above, includes many of the mediators that are considered as potential promotors of ACD (see Mechanisms of anaemia of chronic disease: an overview). This makes the hypothesis of an association between the two conditions plausible, but does not

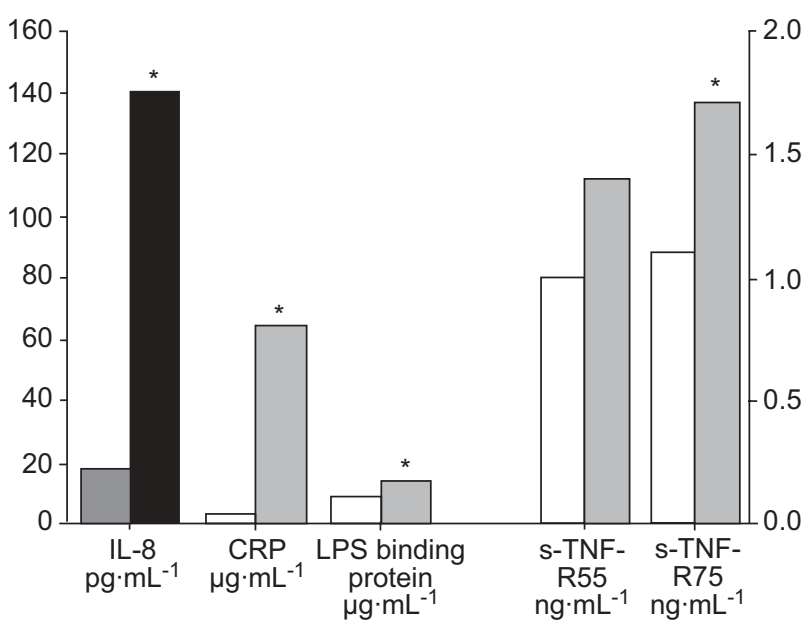

FIGURE 1. Levels of inflammatory markers in patients with chronic obstructive pulmonary disease (COPD; $\square$ ) and healthy subjects ( $\square$ ). $\square$ : measurements for healthy subjects in $\mathrm{pg} \cdot \mathrm{mL}^{-1} ; \mathbf{\square}$ : measurements for COPD patients in $\mathrm{pg} \cdot \mathrm{mL}^{-1}$. The three left-hand sets of columns refer to the left-hand y axis; the two right-hand sets of columns refer to the right-hand y axis. IL-8: interleukin-8; CRP: C-reactive protein LPS, lipopolysaccharide; s-TNF-R55: soluble tumour necrosis factor receptor 55; sTNF-R75: soluble tumour necrosis factor receptor 75. *: $\mathrm{p}<0.05$. Modified from [22] with permission from the publisher. 
prove that COPD actually disrupts erythropoiesis. Is it possible to go further than that? An apparent lack of polycythaemic response to hypoxaemia in COPD has been noted in early studies [31, 32]. Recently, JoHN et al. [12] found that among 101 severe COPD patients (FEV1 $37 \pm 2 \%$ pred), 13 were anaemic. In these patients, the serum levels of CRP and IL-6 were significantly higher than in a group of control subjects. CRP was significantly higher in the anaemic COPD patients than in the nonanaemic patients; this was not the case for IL-6, IL-8 or IL-10. The anaemic COPD patients exhibited significantly elevated levels of erythropoietin compared with the nonanaemic patients $\left(41.8 \pm 25.4\right.$ versus $\left.16.3 \pm 2.9 \mathrm{U} \cdot \mathrm{L}^{-1}\right)$. There was a significant inverse correlation of haemoglobin versus erythropoietin, indicating the presence of erythropoietin resistance. The association of inflammation and erythropoietin resistance is typical of ACD, and therefore this study presents an assumed causative relationship between COPD and ACD. In this study, there was no relationship between anaemia and weight loss or cachexia, suggesting that the development of anaemia can be independent of nutritional factors. In another situation of chronic respiratory insufficiency, TSANTES et al. [33] compared the dynamics of erythropoiesis in nine patients with idiopathic pulmonary fibrosis (IPF) and nine controls. Although haemoglobinaemia and serum EPO levels did not differ between patients and controls, patients with IPF had significantly raised levels of serum TNF- $\alpha$, IL- 6 and IL- 8 . The proliferating capacity of RBCs (as measured by the count of burst-forming unit-erythroid-derived colonies) was higher in the patients than in the controls, but the rate of differentiation was lower in the patients. Overall, the authors concluded that there was an increased quantitative response to hypoxia, qualitatively altered by inflammation. In a subsequent study [34], the same group concluded that these features were absent in nonanaemic COPD patients.

It must be emphasised that factors other than inflammation can be responsible for anaemia in COPD patients. Besides the obvious comorbidities (e.g. gastrointestinal bleeding or folate deficiency), malnutrition can play a role and implement a vicious circle of inflammation. Tobacco smoking itself, probably through the associated oxidative stress, interferes with red cell production and with the effects of long-term oxygen therapy on this production [35]. Theophylline has been found to decrease RBC proliferation in COPD patients, but EPO levels were not affected [36]. Finally, oxygen therapy can theoretically blunt hypoxia-driven erythropoiesis in COPD patients, the reality and clinical impact of which would warrant specific investigation.

\section{THE CLINICAL SIGNIFICANCE OF ANAEMIA IN COPD Clinical lessons from heart failure}

In heart failure, the prevalence of anaemia has been shown to be correlated with the severity of the cardiac condition, increasing $7-26 \%$ as the New York Heart Association (NYHA) class deteriorates from I to IV [37]. However, the prevalence may be higher still; it was estimated to be $10-56 \%$ in the analysis of 14 heart failure trials, using a definition of anaemia of haemoglobinaemia $<12 \mathrm{~g} \cdot \mathrm{dL}^{-1}$ [38]. Anaemia in heart failure has been associated with increased hospitalisation rates and diminished exercise capacity [39]. It has also been shown to be an independent negative prognostic factor for mortality [3, 40]. In anaemic heart failure patients, EPO administration improved left ventricular ejection fraction from $28 \%$ to $35 \%$, and NYHA class by one, with a $92 \%$ decrease in hospitalisations compared with before the study [37]. From a functional point of view, raising haemoglobinaemia in heart failure patients alleviates exercise limitation. In 26 anaemic patients with mild-to-moderate heart failure [41], EPO improved haemoglobin concentration $\left(11.0-14.3 \mathrm{~g} \cdot \mathrm{dL}^{-1} ; \mathrm{p}<0.05\right)$, peak oxygen uptake $\left(V^{\prime} \mathrm{O}_{2} ; 11.0-12.7 \mathrm{~mL} \cdot \mathrm{min}^{-1} \cdot \mathrm{kg}^{-1} ; \mathrm{p}<0.05\right)$ and exercise duration $(590-657 \mathrm{~s} ; \mathrm{p}<0.004)$.

The pathogenesis of anaemia in heart failure has not yet been fully elucidated [42] and intervention studies are needed before the causal relationship between anaemia and heart failure outcomes can be ascertained. Nevertheless, the apparently major clinical relevance of anaemia in heart failure is a strong incentive to explore its impact, if any, in COPD. Indeed, findings for COPD similar to those for heart failure could potentially have a significant impact on the management of the disease.

\section{Clinical relevance of anaemia of COPD Mortality}

The strongest evidence of an association (causative or otherwise) between low haemoglobin levels and mortality in COPD patients seems to be provided in the study derived from the database of the French respiratory home care network, the Association Nationale pour le Traitement a Domicile de l'Insuffisance Respiratoire Chronique (ANTADIR) [13]. Among 2,524 COPD patients with an arterial oxygen tension $\left(\mathrm{Pa}, \mathrm{O}_{2}\right)<7.3 \mathrm{kPa}(55 \mathrm{mmHg})$, who were being prescribed longterm oxygen therapy and in whom an haematocrit value was available at the time of prescription, $12.6 \%$ of males and $8.2 \%$ of females were identified as having anaemia according to the WHO definition [10]. This figure corroborates with the observation of JoHN et al. [12]. In the ANTADIR study [13], haematocrit decreased with age and with the degree of obstruction (FEV1/vital capacity). Conversely, haematocrit tended to be greater in patients with the highest values of body mass index, and there was a positive association between haematocrit and carbon dioxide arterial tension $\left(\mathrm{Pa}_{\mathrm{a}} \mathrm{CO}_{2}\right)$. Multivariate analysis emphasised haematocrit as an independent and major predictor of survival, with the 3-yr survival rate decreasing as lower haematocrit values were considered, and polycythaemia being associated with higher survival rates (3-yr survival 24\% (95\% confidence interval (CI) 16-33\%) when haematocrit was $<35 \%$ versus $70 \%(63-76 \%)$ when haematocrit was $>55 \%$; fig. 2). It is worth noting that in the cohort of 207 patients used by CELLI et al. [11] to describe the BODE prognostic index, haematocrit was significantly $(p=0.01)$ higher in the patients who survived $(n=182$, haematocrit $42 \pm 5 \%)$ compared with those who died $(n=25$, haematocrit $39 \pm 5 \%)$.

From a slightly different perspective, two other studies suggest that chronically decreased haemoglobin levels could enfeeble COPD patients and worsen the prognosis of acute decreases in tissue oxygenation. In one of these studies, mortality from gastrointestinal bleeding appeared to be higher in a cohort of 53 COPD patients, compared with bleeding controls without COPD (32\% versus 10\%, respectively; OR 4.3; 95\% CI 1.22-1.48; $\mathrm{p}<0.01)$ and to COPD controls without bleeding $(32 \%$ versus 


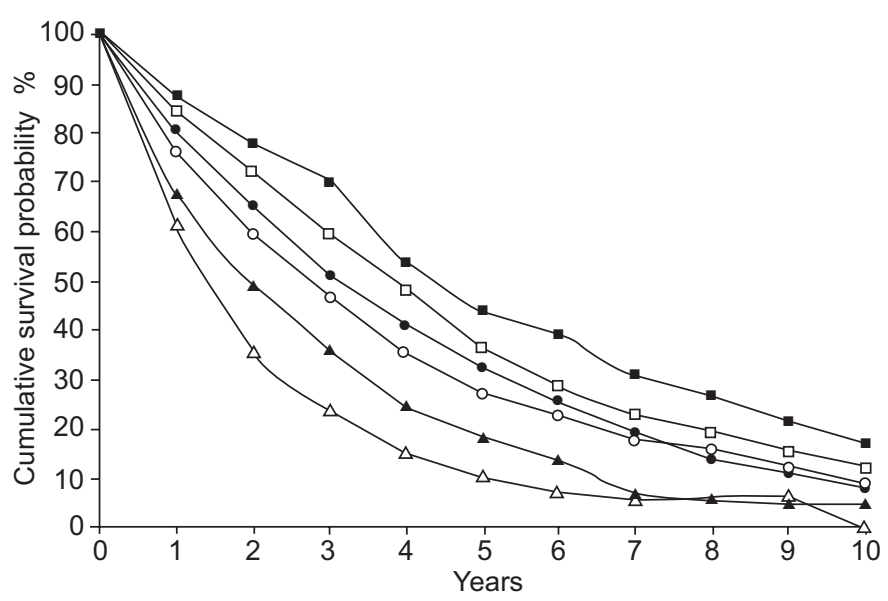

FIGURE 2. Ten-yr survival analysis of the influence of haematocrit calculated by the acturarial method in a cohort of 2,524 chronic obstructive pulmonary disease patients with arterial oxygen tension below $7.3 \mathrm{kPa}(55 \mathrm{mmHg})$ being prescribed long-term oxygen therapy. $\mathbf{\square}: \geqslant 55 \mathrm{yrs}$ age; $\square: 50-54$ yrs age; $: 45-49$ yrs age; O: 40-44 yrs age; $\mathbf{\Lambda}: 35-39 \mathrm{yrs}$ age; $\Delta:<35 \mathrm{yrs}$ age. Modified from [13] with permission from the publisher.

$11 \%$, respectively; OR 3.7; $\mathrm{p}<0.02$ ) [43]. In the other study, suboptimal management (fewer prescribed inhalers), preoperative renal insufficiency, coronary artery disease and reduced haematocrit (average 34\% versus 39\%), were significantly associated $(p=0.002)$ with an unfavourable outcome in COPD patients undergoing elective open abdominal aortic aneurysmectomy [44].

Symptoms and morbidity

The ANTADIR haematocrit study [13] suggests that low haematocrit values are associated with an increased morbidity. Indeed, in this study, there was an inverse relationship between haematocrit and the hospital admission rate, as well as the cumulative duration of hospital stay. Further investigation is required to determine whether a low haematocrit is a promoting factor for hospitalisations or whether frequent hospitalisations contribute to promote anaemia.

Two intervention studies suggest that correcting anaemia in COPD patients can improve their physiological or clinical condition. In one of the studies, blood cell transfusion in anaemic COPD patients was shown to lead to a significant reduction in both minute ventilation $\left(V^{\prime} \mathrm{E}\right)$ and work of breathing (WOB) [45]. In the study, 10 patients with COPD (mean FEV1 $0.55 \mathrm{~L}$ ) were compared with 10 patients without lung disease before and after receiving $\mathrm{RBC}$ transfusion. In the COPD group, the mean $V^{\prime} \mathrm{E}$ decreased from $9.9 \pm 1.0 \mathrm{~L} \cdot \mathrm{min}^{-1}$ to $8.2 \pm 1.2 \mathrm{~L} \cdot \mathrm{min}^{-1} \quad(\mathrm{p}<0.0001)$ and WOB decreased from $1.03 \pm 0.24 \mathrm{WOB} \cdot \mathrm{L}^{-1}$ to $0.85 \pm 0.21$ WOB $\cdot \mathrm{L}^{-1}(\mathrm{p}<0.0001$; fig. 3 ). In patients without COPD, haemoglobin was increased by a similar degree but there was no change in ventilation and gas exchange. It is worth noting that the fall in $V^{\prime} \mathrm{E}$ in the COPD patients translated into a rise in $\mathrm{Pa}_{1} \mathrm{CO}_{2}$ from $5.1 \mathrm{kPa}$ to $5.8 \mathrm{kPa}$ ( $38.3 \mathrm{mmHg}$ to $43.6 \mathrm{mmHg} ; \mathrm{p}<0.05$ ) and a concomitant fall in $\mathrm{Pa}_{2} \mathrm{O}_{2}$ from $7.6 \mathrm{kPa}$ to $7.0 \mathrm{kPa}$ ( $57.1 \mathrm{mmHg}$ to $52.6 \mathrm{mmHg}$; $\mathrm{p}<0.05)$. This is in line with the negative correlation between haematocrit and $\mathrm{Pa}_{\mathrm{a}} \mathrm{CO}_{2}$ evidenced by the ANTADIR study [13]. In the other study, SCHONHÖFER et al. [46] described a series of
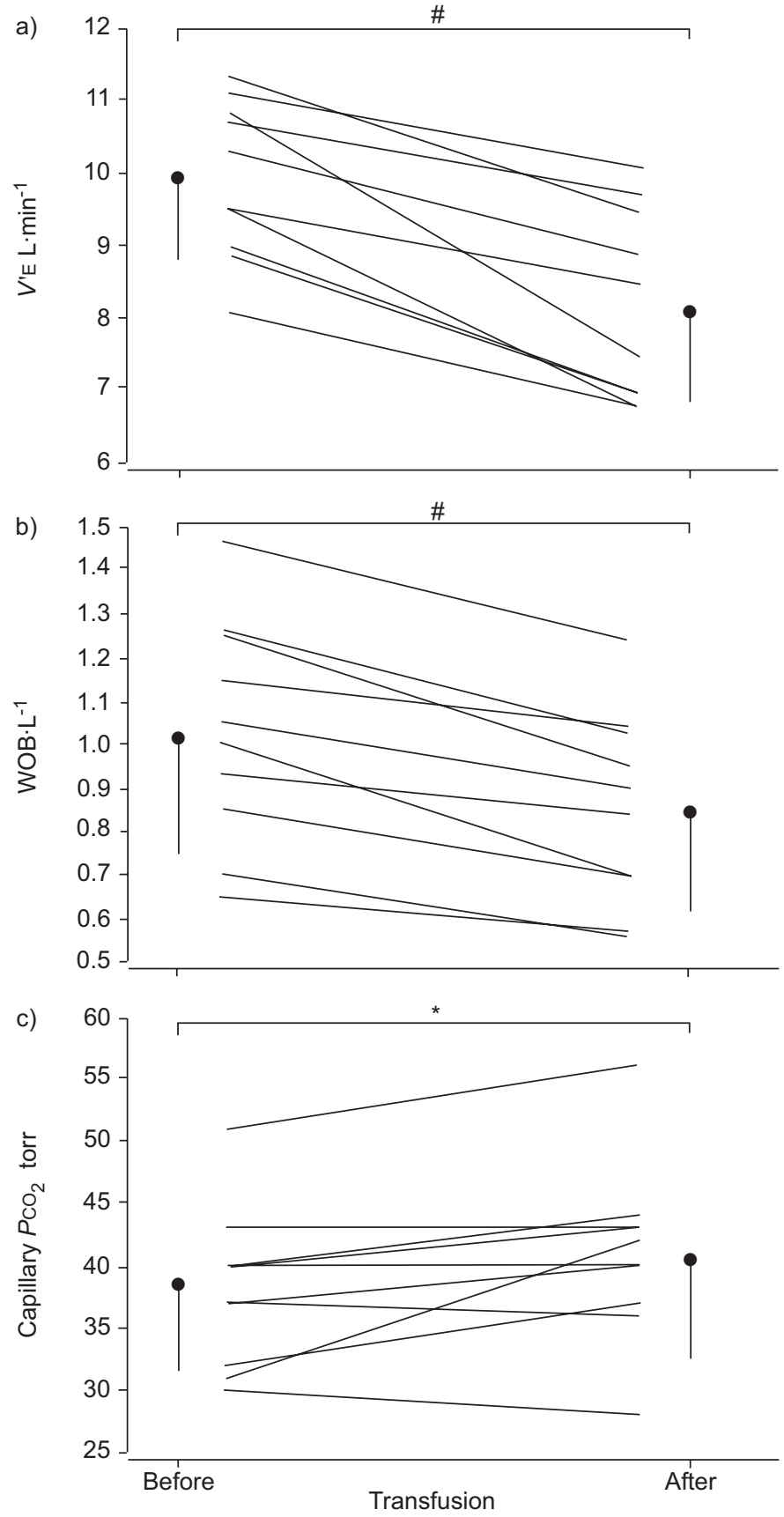

FIGURE 3. Minute ventilation $\left(V^{\prime} E\right)$, work of breathing (WOB) and capillary carbon dioxide pressure $\left(\mathrm{PCO}_{2}\right)$ changes with transfusion in patients with severe chronic obstructive pulmonary disease *: $p<0.05$; ${ }^{*}: p<0.0001$. Modified from [45] with permission from the publisher.

five ventilator-dependent COPD patients, all of whom had anaemia (mean haemoglobin $8.7 \mathrm{~g} \cdot \mathrm{dL}^{-1}$ ) at the time of admission. They received a whole-blood transfusion, raising haemoglobin levels to $>12 \mathrm{~g} \cdot \mathrm{dL}^{-1}$, and all were then successfully weaned from the ventilator, 1-4 days post-transfusion.

\section{Pathophysiological basis for the benefit of raising haemoglobin in COPD}

Whether raising haemoglobin levels in COPD would decrease mortality remains to be studied and, as with heart failure, it is 
difficult to foresee what the corresponding mechanisms would be. However, there are pathophysiological arguments that support the idea that raising haemoglobin in anaemic COPD patients (and possibly nonanaemic patients) could improve dyspnoea and exercise tolerance, as it does in heart failure [41].

\section{Breathing pattern}

Any therapeutic intervention reducing $V^{\prime} \mathrm{E}$ and/or polypnoea in COPD could decrease dynamic hyperinflation and, as a result, alleviate dyspnoea and improve exercise tolerance. The observation of SCHONHÖFER et al. [45], that RBC transfusion in COPD patients does reduce $V^{\prime} E$ (see above), thus allows the speculation that a reduction in the degree of dynamic hyperinflation could be expected in response to an increase in the haemoglobin level. This would be very similar to the effects of oxygen administration prior to exercise in severe COPD patients $[47,48]$.

\section{Haemodynamics and gas exchange}

The efficiency of pulmonary gas exchange is connected to haemoglobin levels [49], and raising haemoglobinaemia improves haemodynamics. As a result, the improved cardiorespiratory interaction should, as in other clinical settings, contribute to putative improvements in exercise ability in COPD.

\section{Skeletal muscle function}

There is a large body of evidence, much of which is beyond the scope of this review, which supports the view that skeletal muscle dysfunction is a major contributor to exercise limitation in COPD [50-54]. It could therefore be hypothesised that the effects observed on muscle performance in nonanaemic athletes with EPO may also be seen in COPD patients. It may not be that simple, however, as illustrated in studies of chronic renal failure patients. EPO has been associated with positive effects on muscle $\mathrm{O}_{2}$ transport during exercise in patients with chronic renal failure [55], with an increase in $\mathrm{O}_{2}$ occurring in proportion to the increase in blood flow. Such an effect would theoretically be useful in COPD-related muscle dysfunction. However, probably because of muscular abnormalities due to uraemia [56], EPO in chronic renal failure patients does not improve peak $V^{\prime} \mathrm{O}_{2}$ as much as expected from the rise in haemoglobinaemia. The relationship between muscle $\mathrm{O}_{2}$ delivery, blood flow and haemoglobin is thus a complex one and would have to be the object of specific studies in COPD for further clarification.

\section{CONCLUSION}

Currently available arguments suggest: 1) that haemoglobinaemia in COPD could be determined by the balance between the stimulating effects of hypoxia on EPO production and inflammation-induced EPO resistance; 2) that, as with heart failure, anaemia in COPD could have a negative prognostic impact, associated with a reduced survival and increased morbidity; and 3) that anaemia could worsen dyspnoea and exercise limitation.

However, the current evidence is very fragmented and preliminary. The real prevalence of anaemia in chronic obstructive pulmonary disease has not yet been ascertained; the possibility of an association between anaemia and disease severity needs to be explored; the clinical impact of anaemia in chronic obstructive pulmonary disease is yet to be established; and, finally, the effects of raising haemoglobinaemia on physiological parameters and on clinical outcomes are speculative. For all these reasons, it seems justifiably important to systematically and prospectively study the mechanisms and impact of anaemia on chronic obstructive pulmonary disease, in order to determine whether correcting low haemoglobin levels has a place in the therapeutic arsenal against this disease.

\section{ACKNOWLEDGEMENTS}

The authors are grateful to $C$. Robinson for his help with the manuscript.

\section{REFERENCES}

1 Weiss G, Goodnough LT. Anemia of chronic disease. N Engl J Med 2005; 352: 1011-1023.

2 Means RT Jr. Recent developments in the anemia of chronic disease. Curr Hematol Rep 2003; 2: 116-121.

3 Ezekowitz JA, McAlister FA, Armstrong PW. Anemia is common in heart failure and is associated with poor outcomes: insights from a cohort of 12065 patients with new-onset heart failure. Circulation 2003; 107: 223-225.

4 Agusti AG, Noguera A, Sauleda J, Sala E, Pons J, Busquets $X$. Systemic effects of chronic obstructive pulmonary disease. Eur Respir J 2003; 21: 347-360.

5 Oudijk EJ, Lammers JW, Koenderman L. Systemic inflammation in chronic obstructive pulmonary disease. Eur Respir J Suppl 2003; 22: Suppl. 46, 5s-13s.

6 Wouters EF. Chronic obstructive pulmonary disease. 5: systemic effects of COPD. Thorax 2002; 57: 1067-1070.

7 Gan WQ, Man SF, Senthilselvan A, Sin DD. Association between chronic obstructive pulmonary disease and systemic inflammation: a systematic review and a metaanalysis. Thorax 2004; 59: 574-580.

8 Spruit MA, Gosselink R, Troosters T, et al. Muscle force during an acute exacerbation in hospitalised patients with COPD and its relationship with CXCL8 and IGF-I. Thorax 2003; 58: 752-756.

9 Wedzicha JA, Seemungal TA, MacCallum PK, et al. Acute exacerbations of chronic obstructive pulmonary disease are accompanied by elevations of plasma fibrinogen and serum IL-6 levels. Thromb Haemost 2000; 84: 210-215.

10 World Health Organization. Nutritional Anemias: Report of a WHO Scientific Group. In: WHO Technical Report Series 405. Geneva, World Health Organization, 1968; pp. 1-37.

11 Celli BR, Cote CG, Marin JM, et al. The body-mass index, airflow obstruction, dyspnea, and exercise capacity index in chronic obstructive pulmonary disease. $N$ Engl J Med 2004; 350: 1005-1012.

12 John M, Hoernig S, Doehner W, Okonko DD, Witt C, Anker SD. Anemia and inflammation in COPD. Chest 2005; 127: 825-829.

13 Chambellan A, Chailleux E, Similowski T, and the ANTADIR observatory group. Prognostic value of the hematocrit in patients with severe COPD receiving longterm oxygen therapy. Chest 2005; 128: 1201-1208. 
14 Means RT Jr. Advances in the anemia of chronic disease. Int J Hematol 1999; 70: 7-12.

15 Salvarani C, Casali B, Salvo D, et al. The role of interleukin 1 , erythropoietin and red cell bound immunoglobulins in the anaemia of rheumatoid arthritis. Clin Exp Rheumatol 1991; 9: 241-246.

16 Moldawer LL, Marano MA, Wei H, et al. Cachectin/tumor necrosis factor-alpha alters red blood cell kinetics and induces anemia in vivo. FASEB J 1989; 3: 1637-1643.

17 van der Meer P, Voors AA, Lipsic E, van Gilst WH, van Veldhuisen DJ. Erythropoietin in cardiovascular diseases. Eur Heart J 2004; 25: 285-291.

18 Rice L, Alfrey CP, Driscoll T, Whitley CE, Hachey DL, Suki W. Neocytolysis contributes to the anemia of renal disease. Am J Kidney Dis 1999; 33: 59-62.

19 Rogers J, Lacroix L, Durmowitz G, Kasschau K, Andriotakis J, Bridges KR. The role of cytokines in the regulation of ferritin expression. Adv Exp Med Biol 1994; 356: $127-132$.

20 Voulgari PV, Kolios G, Papadopoulos GK, Katsaraki A, Seferiadis K, Drosos AA. Role of cytokines in the pathogenesis of anemia of chronic disease in rheumatoid arthritis. Clin Immunol 1999; 92: 153-160.

21 Celli BR, MacNee W. Standards for the diagnosis and treatment of patients with COPD: a summary of the ATS/ ERS position paper. Eur Respir J 2004; 23: 932-946.

22 Schols AM, Buurman WA, Staal van den Brekel AJ, Dentener MA, Wouters EF. Evidence for a relation between metabolic derangements and increased levels of inflammatory mediators in a subgroup of patients with chronic obstructive pulmonary disease. Thorax 1996; 51: 819-824.

23 MacNee W. Oxidants/antioxidants and COPD. Chest 2000; 117: 303S-317S.

24 MacNee W. Neutrophil traffic and COPD. Eur Respir Rev 1997; 7: 124-127.

25 Selby C, Drost E, Lannan S, Wraith PK, MacNee W. Neutrophil retention in the lungs of patients with chronic obstructive pulmonary disease. Am Rev Respir Dis 1991; 143: 1359-1364.

26 de Godoy I, Donahoe M, Calhoun WJ, Mancino J, Rogers RM. Elevated TNF-alpha production by peripheral blood monocytes of weight-losing COPD patients. Am J Respir Crit Care Med 1996; 153: 633-637.

27 Di Francia M, Barbier D, Mege JL, Orehek J. Tumor necrosis factor-alpha levels and weight loss in chronic obstructive pulmonary disease. Am J Respir Crit Care Med 1994; 150: 1453-1455.

28 Eid AA, Ionescu AA, Nixon LS, et al. Inflammatory response and body composition in chronic obstructive pulmonary disease. Am J Respir Crit Care Med 2001; 164: 1414-1418.

29 Pitsiou G, Kyriazis G, Hatzizisi O, Argyropoulou P, Mavrofridis E, Patakas D. Tumor necrosis factor-alpha serum levels, weight loss and tissue oxygenation in chronic obstructive pulmonary disease. Respir Med 2002; 96: 594-598.

30 Cano NJ, Pichard C, Roth H, et al. C-reactive protein and body mass index predict outcome in end-stage respiratory failure. Chest 2004; 126: 540-546.

31 Baldwin EF, Cournand A, Richards DW. Pulmonary insufficiency. III. A study of 122 cases of chronic pulmonary emphysema. Medicine 1949; 28: 201-210.
32 Wilson RH, Borden C, Ebert RV. Adaptation to anoxia in chronic pulmonary emphysema. Arch Int Med 1951; 88: 581-585.

33 Tsantes A, Tassiopoulos S, Papadhimitriou SI, et al. Suboptimal erythropoietic response to hypoxemia in idiopathic pulmonary fibrosis. Chest 2003; 124: 548-553.

34 Tsantes A, Bonovas S, Tassiopoulos S, et al. A comparative study of the role of erythropoietin in the pathogenesis of deficient erythropoiesis in idiopathic pulmonary fibrosis as opposed to chronic obstructive pulmonary disease. Med Sci Monit 2005; 11: CR177-CR181.

35 Calverley PM, Leggett RJ, McElderry L, Flenley DC. Cigarette smoking and secondary polycythemia in hypoxic cor pulmonale. Am Rev Respir Dis 1982; 125: 507-510.

36 Tsantes AE, Tassiopoulos ST, Papadhimitriou SI, et al. Theophylline treatment may adversely affect the anoxiainduced erythropoietic response without suppressing erythropoietin production. Eur J Clin Pharmacol 2003; 59: 379-383.

37 Silverberg DS, Wexler D, Blum M, et al. The use of subcutaneous erythropoietin and intravenous iron for the treatment of the anemia of severe, resistant congestive heart failure improves cardiac and renal function and functional cardiac class, and markedly reduces hospitalizations. J Am Coll Cardiol 2000; 35: 1737-1744.

38 Komajda M. Prevalence of anemia in patients with chronic heart failure and their clinical characteristics. I Card Fail 2004; 10: S1-S4.

39 McMurray JJ. What are the clinical consequences of anemia in patients with chronic heart failure? J Card Fail 2004; 10: S10-S12.

40 Horwich TB, Fonarow GC, Hamilton MA, MacLellan WR, Borenstein J. Anemia is associated with worse symptoms, greater impairment in functional capacity and a significant increase in mortality in patients with advanced heart failure. J Am Coll Cardiol 2002; 39: 1780-1786.

41 Mancini DM, Katz SD, Lang CC, LaManca J, Hudaihed A, Androne AS. Effect of erythropoietin on exercise capacity in patients with moderate to severe chronic heart failure. Circulation 2003; 107: 294-299.

42 Okonko DO, Anker SD. Anemia in chronic heart failure: pathogenetic mechanisms. J Card Fail 2004; 10: S5-S9.

43 Cappell MS, Nadler SC. Increased mortality of acute upper gastrointestinal bleeding in patients with chronic obstructive pulmonary disease. A case controlled, multiyear study of 53 consecutive patients. Dig Dis Sci 1995; 40: 256-262.

44 Upchurch GR Jr, Proctor MC, Henke PK, et al. Predictors of severe morbidity and death after elective abdominal aortic aneurysmectomy in patients with chronic obstructive pulmonary disease. J Vasc Surg 2003; 37: 594-599.

45 Schonhöfer B, Wenzel M, Geibel M, Kohler D. Blood transfusion and lung function in chronically anemic patients with severe chronic obstructive pulmonary disease. Crit Care Med 1998; 26: 1824-1828.

46 Schonhöfer B, Bohrer $H$, Kohler D. Blood transfusion facilitating difficult weaning from the ventilator. Anaesthesia 1998; 53: 181-184.

47 Emtner M, Porszasz J, Burns M, Somfay A, Casaburi R. Benefits of supplemental oxygen in exercise training in nonhypoxemic chronic obstructive pulmonary disease patients. Am J Respir Crit Care Med 2003; 168: 1034-1042. 
48 Somfay A, Porszasz J, Lee SM, Casaburi R. Dose-response effect of oxygen on hyperinflation and exercise endurance in nonhypoxaemic COPD patients. Eur Respir J 2001; 18: 77-84.

49 Wagner PD. Diffusion and chemical reaction in pulmonary gas exchange. Physiol Rev 1977; 57: 257-312.

50 Skeletal muscle dysfunction in chronic obstructive pulmonary disease. A statement of the American Thoracic Society and European Respiratory Society. Am J Respir Crit Care Med 1999; 159: S1-S40.

51 Richardson RS, Leek BT, Gavin TP, et al. Reduced mechanical efficiency in chronic obstructive pulmonary disease but normal peak $\mathrm{VO}_{2}$ with small muscle mass exercise. Am J Respir Crit Care Med 2004; 169: 89-96.

52 Sauleda J, Garcia-Palmer F, Wiesner RJ, et al. Cytochrome oxidase activity and mitochondrial gene expression in skeletal muscle of patients with chronic obstructive pulmonary disease. Am J Respir Crit Care Med 1998; 157: 1413-1417.

53 Maltais F, LeBlanc P, Whittom F, et al. Oxidative enzyme activities of the vastus lateralis muscle and the functional status in patients with COPD. Thorax 2000; 55: 848-853.

54 Barreiro E, de la Puente B, Minguella J, et al. Oxidative stress and respiratory muscle dysfunction in severe chronic obstructive pulmonary disease. Am J Respir Crit Care Med 2005; 171: 1116-1124.

55 Marrades RM, Roca J, Campistol JM, et al. Effects of erythropoietin on muscle $\mathrm{O}_{2}$ transport during exercise in patients with chronic renal failure. J Clin Invest 1996; 97: 2092-2100.

56 Marrades RM, Alonso J, Roca J, et al. Cellular bioenergetics after erythropoietin therapy in chronic renal failure. J Clin Invest 1996; 97: 2101-2110. 